\title{
Art \& Science Works Together Through A WEBINAR On COVID-19: An Exciting Self-Directed E-Learning Experience
}

\author{
Dr. Abdul Sattar Khan*1, Mr. Jose Karlo Pangan ${ }^{2}$ and Ms. Maria Cristina Samonte ${ }^{3}$ \\ ${ }^{1,3}$ Department of Family \& Community Medicine, College of Medicine, King Faisal University \\ ${ }^{2}$ Bio-Medical Sciences Department, College of Medicine, King Faisal University
}

\begin{tabular}{ll}
\hline Article History & $\begin{array}{l}\text { Abstract: Purpose: This brief communication signifies the effectiveness of an organizing } \\
\text { and conducting of a webinar on COVID-19 by the medical students. Method: Due to } \\
\text { Received: } 15.08 .2020\end{array}$ \\
Accepted: 01.09 .2020 & $\begin{array}{l}\text { COVID-19 outbreak the College of Medicine, King Faisal University decided to shift all } \\
\text { undergraduates as well as postgraduate Courses online. Therefore, all courses were shifted } \\
\text { to on-line courses. The challenge for some courses regarding practical exposure and new } \\
\text { experimentation. In Social Medicine course of fifth year MBBS, a webinar was designed on } \\
\text { current COVID-19 outbreak as a pilot study. It was very well appreciated and students } \\
\text { learned some new items, enhance deep leaning about the topic, and very well verse about the }\end{array}$ \\
hournal homepage: & $\begin{array}{l}\text { social dogma related to this issue. Results: Out of total 25 registered participants, } 20 \text { have } \\
\text { submitted an evaluation of the webinar. Majority (95\%) agreed that presentations } \\
\text { background and design were appropriate, presented almost all objectives, and presentations } \\
\text { contain required knowledge etc., except a few comments are also mentioned regarding } \\
\text { further improvement. Conclusion: It was an exciting experience for enhancing learning by }\end{array}$ \\
active experimentation that definitely enhanced the deep learning. & Keywords: Social Medicine, COVID-19, Webinar.
\end{tabular}

Copyright ( 12020 The Author(s): This is an open-access article distributed under the terms of the Creative Commons Attribution 4.0 International License (CC BY-NC 4.0) which permits unrestricted use, distribution, and reproduction in any medium for non-commercial use provided the original author and source are credited.

\section{INTRODUCTION}

Due to dominance of the internet in learning as an emerging tool, the learning environment of medical education is entirely different as compared to 20 years back and medical students around the world (Ruiz, Mintzer and Leipzig, 2006) now increasingly utilize elearning platforms. Indeed, it has the same advantages as mentioned earlier including enhancement of selfdirected learning (Ruiz, Mintzer and Leipzig, 2006). However, it could be enjoyable and effective, but it is believed that it cannot replace traditional didactic methods and students prefer to have blended pedagogical approaches according to Warnecke and Pearson (2011). This debate still not yet concluded though some learning management systems (Hartshorne and Aijan, 2009) have introduced and ready to teach virtually many items relevant even for clinical trainings. However, due to devastating effect of the COVID-19 outbreak, the learning methodology absolutely has shifted to e-learning and brought many challenges to all faculty as well as students.

The King Faisal University is one of the universities in the kingdom, which quickly responded to the Ministry of Education (remove revelation) and shifted to and shifted to e-learning without wasting the time of the students. We use the Blackboard system mainly for teaching, and learning purposes. Therefore, it was a kind of compulsion to reshape the courses, which are purely related to clinical / community training to involve students maximally and enhance their learning without compromising quality of education. However, during this shifting from on-site to online, the teaching faculty faced many challenges. The Social Medicine course is one of the courses taught in the final year of MBBS program and designed in a way to expose students to social health care issues by visiting some community places for direct exposure to community issues; for example cigarette smoking cession centre etc. Since it is shifted to online, the community visits and report writing as it was designed is not possible to apply (Khan, 2016). Therefore, it was re-shaped and in order to address some community issues through students, we have designed a WEBINAR relevant to a COVID-19 pandemic.

\section{Objectives}

The objectives of this educational on-line activity aside from gaining knowledge, is to give our students the opportunity to be exposed to essential topics that will allow them to create community awareness, discuss significant social aspects of the outbreak, practice organization and management of a 
webinar, and enhance their health education and presentation skills.

\section{Preparation of the WEBINAR}

The webinar is designed as part of a course Social Medicine, which has 1.5 credit hours in final year of MBBS. It was conducted first time as a pilot study in order to assess the feasibility for conducting a webinar on a large scale. The main theme was selected by the course coordinator i.e., COVID-19: In the frontline and sub-titles included after a thorough brain storming among course coordinator and students were; Global \& Local Epidemiology, Management, Prevention and herd immunity of COVID-19. The four speaker students have selected one topic for each presenter. The blackboard system was utilized already for e-learning purposes for all classes because it is allowed to create a session for a class or seminar as well as recording it. In preparation of the webinar, we have created a mock session for two hours Presentations with questions and answer, and sent the session link to the all participants. Two producers acted as as moderators for time management and Managed the question and answer session. A Google Form evaluation was developed with seven simple statements based on Likert scale of agreement. The data were entered into the IBM SPSS version 21 and calculated the frequency and percentages for their agreement.

\section{Evaluation of the WEBINAR}

A total of twenty-five (25) faculty members have participated in the webinar, however Twenty (20) (80\%) have completed the evaluation form for the webinar. Out of total, nearly $95 \%$ participants have agreed that presentations background and design were appropriate, presentations almost all objectives, and presentations contain required knowledge etc. (Table 1). The participants regarding webinar have given the following comments:

1. As medical students, they should get more recent information and good luck in future.

2. Keep working on this subject for research

3. May include more flowcharts and information till yesterday

4. Recent updates can be added. Generally, the presentation is good. Well done.

5. Update the information when presenting figures e.g. population, cite or mention the source and include more pictures

\section{DISCUSSION}

Adult learning is based on Kolb's experiential learning cycle (Arkoful and Abaidoo, 2015) is based on four principles concrete experience, reflective observation of the new experience, abstract conceptualization, and active experimentation. Therefore, a new paradigm shift has been happening during the last two to three decades and andragogy prevails at higher level of medical education. Kolb's learning cycle applies because it has high impact and deep learning as an outcome. The Social Medicine course at our college follows the same principles for more learning (Kolb, 2005). However, due to current COVID-19 pandemic we shifted to e-learning process and utilized a learning management system that is Blackboard (Khan, 2016).

The virtual or e-learning is widely accepted throughout the world in the last two to three decades due to many reasons. For instance, it is a flexible teaching and learning method if the main concern is time management. Students can have access to huge amount of information in limited time, students may use different forums for the discussion purposes, a variety of methods can be used through e-learning, it is a costeffective method and many more (Arkoful and Abaidoo, 2015). In fact, it has limitations too in terms to apply Kolb's experiential learning cycle (Kolb, 2005).

The challenge of this course is that it is designed in a way to expose our students to community directly (Khan, 2016) in order to aware the students In dealing with social issues and integration to other courses in fifth year courses. However, it became more challenging during COVID-19 outbreak because all courses conduct via e-learning. Moreover, we also need to cover a situation where something new happened, new learning can happen, the students must have new experience, and can work on new idea and do an active experimentation (Arkoful and Abaidoo, 2015). Thus, we designed a webinar on current COVID-19 outbreak and tried to fulfil all objectives as mentioned by Kolb's experiential learning cycle (Kolb, 2005). It was a mandatory activity for the students and they were asked to prepare presentations and present in front of the faculty members. It was a pilot study to identify whether this is applicable for mass level activity by the students. An evaluation from the participants depict that majority either strongly agree or agree for conducting very well organized webinar and presentations were also appreciated from the participants. However, there were some points of improvement also raised by the participants such as they should include some more recent information and have some pictorial presentations through flow charts etc. Conclusively, it was an exciting experience for enhancing learning by active experimentation that definitely enhanced the deep learning.

\section{REFERENCES}

1. Arkorful, V., \& Abaidoo, N. (2005). The role of elearning, advantages and disadvantages of its adoption in higher education. International Journal of Instructional Technology and Distance Learning, pp. Jan: 12(1), 29-42.

2. Hartshorne, R. \& Ajjan, H. (2009). December. Examining student decisions to adopt Web 2.0 
technologies: theory and empirical tests. Journal of Computing in Higher Education, p. 1:21 (3):183.

3. JG, R., Mintzer, M., \& Leipzig, R. (2006). The Impact of E-Learning in Medical Education. Academic Medicine, pp. 81 (3), 207-12.

4. Khan, A. S. (2016). Social Medicine Integration for Clinical Year in Arab World. MedEd Publish, p. Dec 19, 5.
5. Kolb, A., \& Kolb, D. (2005). Learning Styles and Learning spaces: Enhacing experiential learning in higher education. Academy of management learning \& education, pp. Jun 1:4 (2),193-212.

6. Warnecke, E., \& Pearson, S. (2011). Medical Students' perceptions of using e-learning to enhance the acquisition of consulting skills. Australas Medical Journal. 